Gut, 1983, 24, 28-32

\title{
Effect of sodium taurocholate on gastric secretion in patients with duodenal ulceration
}

\author{
M R LEWIN, E PIFANO, R D DANIEL, P B BOULOS, and C G CLARK \\ From the Department of Surgery, School of Medicine, University College London, The Rayne Institute, \\ London
}

SUMmARY The effect of sodium taurocholate instillation on the stimulated stomachs of patients with duodenal ulceration has been investigated. Instillation into the stomach of sodium taurocholate significantly reduced pentagastrin stimulated volume and outputs of both acid and sodium, with no change in the calculated volume of duodenogastric reflux. These observations are not consistent with the back-diffusion theory, but suggest direct parietal cell inhibition of gastric secretion by sodium taurocholate.

Reflux of bile salts from the duodenum into the stomach has long been implicated in the aetiology of gastric ulcer. ${ }^{12}$ The mechanism has generally been assumed to be caused by damage to the mucosa, and hyposecretion of acid has often been observed. ${ }^{34}$ The mechanism of acid hyposecretion has been considered to be due to back-diffusion of hydrogen ion, replaced by sodium ion moving in the opposite direction into the lumen of the stomach. ${ }^{5}$ Our observations, using an in vivo model in the rat, did not support this hypothesis. ${ }^{6}$ We have, therefore, extended these observations to study the effect of the bile salt sodium taurocholate introduced into the stomach in man during maximal stimulation of gastric secretion with pentagastrin.

\section{Methods}

Nine patients with endoscopically proven duodenal ulceration were studied after obtaining informed consent. Each subject fasted and abstained from tobacco from midnight and from all medication known to affect gastric secretion for at least 48 hours before the study. The subjects lay semirecumbent on a couch and a specially prepared double lumen nasogastric tube ${ }^{7}$ was passed through the patient's nostril and its position in the stomach assessed by the water recovery test. ${ }^{8}$ The tube was then connected to an electric suction pump (Roberts pump) and a suction of about $10 \mathrm{~mm} \mathrm{Hg}$ was maintained. The resting juice was discarded, and, after collecting a basal secretion for 30 minutes, pentagastrin (at a dose selected to give a maximal secretory response) was infused intravenously for three hours at a rate of $0.6 \mu \mathrm{g} / \mathrm{kg} / \mathrm{h}$ using a Palmer constant infusion pump. Gastric aspirates were collected every 10 minutes during the three hour period of maximal stimulation. In six patients, at the completion of the first hour, sodium taurocholate (NaTC) was instilled through the fine inner tube of the prepared nasogastric tube for one hour at a rate of $200 \mu \mathrm{mol} / \mathrm{h}$ at $6 \mathrm{ml} / 10 \mathrm{~min}$. This selected dose represented a concentration greater than an identified threshold level of bile acid in the gastric juice of symptomatic patients with bile reflux gastritis after partial gastrectomy. ${ }^{9}$ In three control patients, deionised water instead of NaTC was instilled at the same rate of $6 \mathrm{ml} / 10 \mathrm{~min}$. At the end of one hour, NaTC or water instillation was stopped and 10 minute aspirates were collected for a further one hour. The pentagastrin infusion was maintained throughout the three hour study so that there were one hour periods before and after an hour period of NaTC or water instillation into the stomach.

The volume of each sample of gastric juice was measured, and, after filtration through a Whatman No. 1 filter paper, the titratable acidity and the concentration of sodium were determined. Acidity was measured by titration against $0 \cdot 1 \mathrm{M}$ sodium hydroxide using phenolphthalein as an indicator. Sodium concentration was measured by a standard automated flame photometric method.

CALCULATIONS

The results for each one hour period during the 
three hour study were expressed in terms of observed volume, acid output, sodium output, and calculated volume of duodenogastric reflux. The observed volume was the total volume of aspirated gastric juice in one hour corrected for the volume of NaTC or water during the period of instillation and expressed in $\mathrm{ml} / \mathrm{h}$. The acid output was calculated from the observed volume and titratable acidity and expressed in $\mathrm{mmol} / \mathrm{h}$. The sodium output was calculated from the sodium concentration and observed volume in 10 minute samples and expressed in $\mathrm{mmol} / \mathrm{h}$ after correction for the sodium concentration instilled during the sodium taurocholate instillation. The duodenogastric reflux was calculated from the sodium output in each 10 minute sample by the formula described by Hobsley ${ }^{10}$ and expressed in $\mathrm{ml} / \mathrm{h}$. As a volume marker was not used in these studies, no calculation can be made for pyloric losses. Only the last three 10 minute aspirates during the first hour of pentagastrin stimulation were measured, as they represented the plateau of secretion during this initial period of stimulation and were then expressed per hour. For the other periods, the whole 10 minute aspirates during the hour were measured.

The results during the initial and the final periods when no sodium taurocholate was instilled were compared separately with the period of sodium taurocholate instillation using the Wilcoxon rank sum test for paired samples. Because of the small numbers in the control studies, the initial and final periods were combined and compared with the period of water instillation using the Wilcoxon rank sum test for unpaired samples.

The possibility that the results obtained were explicable in terms of the two-component hypothesis of gastric secretion was assessed by correlating for individual patients the median of the hydrogen ion output aginst the median of the volume secreted ${ }^{11}$ during the different periods. The results were expressed as 15 minute outputs for direct comparison of these data with those of Hobsley and Silen. ${ }^{11}$

\section{Results}

\section{CONTROL STUDIES}

The gastric secretion results for the control patients are shown in the Table and Fig. 1. There was no change in the observed volume, the acid or sodium output, and the volume of duodenogastric reflux before, during, or after water instillation.

\section{SODIUM TAUROCHOLATE STUDIES}

The results of sodium taurocholate instillation on gastric secretion are shown in the Table and Fig. 2. The observed volume of secretion during bile salt instillation was significantly reduced from the initial level $(p<0.02)$ and was also significantly less than the observed volume after the instillation had stopped $(p<0.02)$. The observed volume of secretion after cessation of NaTC instillation remained significantly less than the initial observed volume $(\mathrm{p}<0.02)$. The acid output was affected in a similar manner. The acid output during NaTC instillation was significantly less than the output measured both before $(p<0.02)$ and after instillation $(p<0.05)$. The acid output in the final hour remained significantly less than the output in the initial hour $(p<0 \cdot 02)$. The sodium output during NaTC instillation diminished and was significantly less than the output both in the initial period $(p<0.05)$ and in the final period $(p<0.05)$ but the output after the cessation of NaTC instillation did not differ from the initial output. The duodenogastric reflux showed no significant change during the three different periods of the study.

Figure 3 shows the plot of 15 minute hydrogen ion outputs against 15 minute volumes of secretion during the different periods in the individual subjects of the two groups. Correlation analysis showed a significant relationship $(r=0.949$,

Table Medians and ranges of indices of secretion during different periods of water and sodium taurocholate instillation (NaTC) studies

\begin{tabular}{|c|c|c|c|c|c|c|}
\hline \multirow[b]{2}{*}{ Indices } & \multicolumn{3}{|c|}{ Control patients } & \multicolumn{3}{|c|}{ Test patients } \\
\hline & Initial & Water & Final & Initial & $N a T C$ & Final \\
\hline Observed volume $(\mathrm{ml} / \mathrm{h})$ & $\begin{array}{l}350 \\
(312-356)\end{array}$ & $\begin{array}{l}332 \\
(294-401)\end{array}$ & $\begin{array}{l}371 \\
(320-408)\end{array}$ & $\begin{array}{l}459 \\
(344-848)\end{array}$ & $\begin{array}{l}311 \\
(167-387)\end{array}$ & $\begin{array}{l}375 \\
(233-434)\end{array}$ \\
\hline Acid output (mmol/h) & $\begin{array}{l}37 \cdot 6 \\
(29 \cdot 4-41 \cdot 1)\end{array}$ & $\begin{array}{l}34 \cdot 4 \\
(30 \cdot 9-43 \cdot 7)\end{array}$ & $\begin{array}{l}36 \cdot 1 \\
(29 \cdot 8-41 \cdot 2)\end{array}$ & $\begin{array}{l}56 \cdot 6 \\
(35-93)\end{array}$ & $\begin{array}{l}37 \cdot 2 \\
(21-45)\end{array}$ & $\begin{array}{l}39 \cdot 0 \\
(23-47)\end{array}$ \\
\hline Reflux volume $(\mathrm{ml} / \mathrm{h})$ & $\begin{array}{l}0 \cdot 08 \\
(0-3 \cdot 2)\end{array}$ & $\begin{array}{l}6 \cdot 8 \\
(6 \cdot 7-11 \cdot 9)\end{array}$ & $\begin{array}{l}3 \cdot 4 \\
(1 \cdot 7-21 \cdot 6)\end{array}$ & $\begin{array}{l}0 \\
(0-30)\end{array}$ & $\begin{array}{l}1 \cdot 3 \\
(0-14)\end{array}$ & $\begin{array}{l}2 \cdot 0 \\
(0-22)\end{array}$ \\
\hline
\end{tabular}


Fig. 1 Sodium, acid output, and observed volume of secretion, before, during, and after water instillation in three subjects. Medians of the 10 minute and calculated hourly collections during the different periods are shown together with statistical analysis.

PENTAGASTRIN INFUSION

BILE SALT

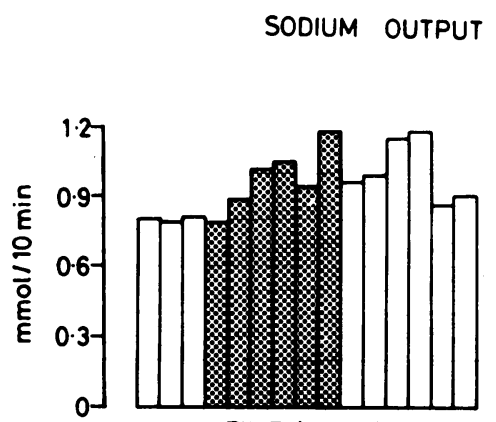

TIME (10min)
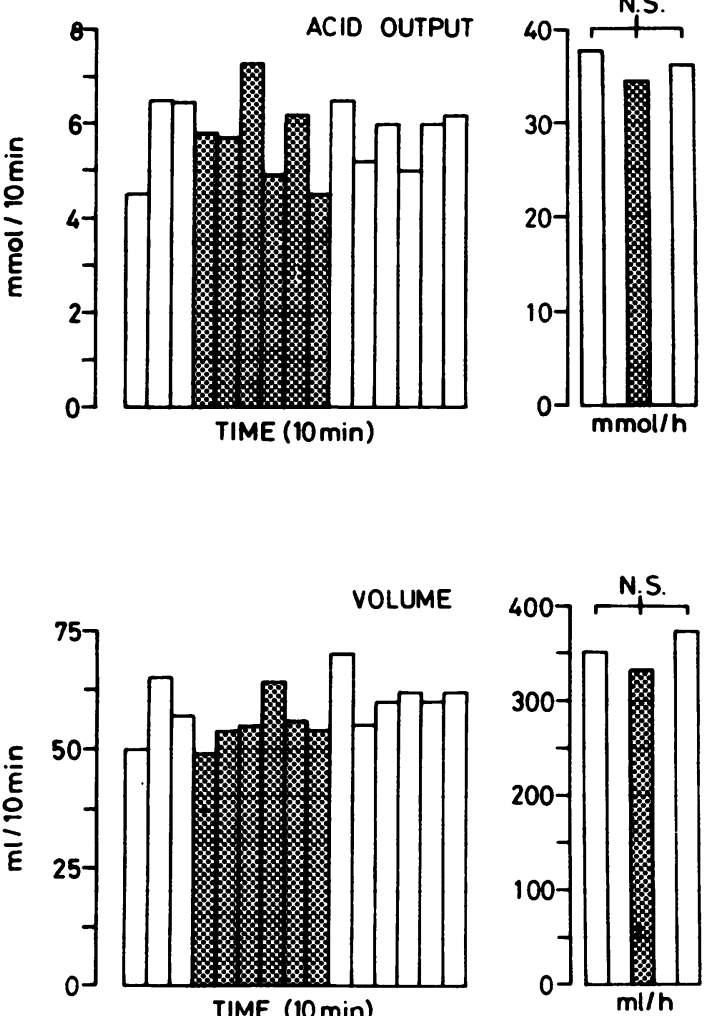
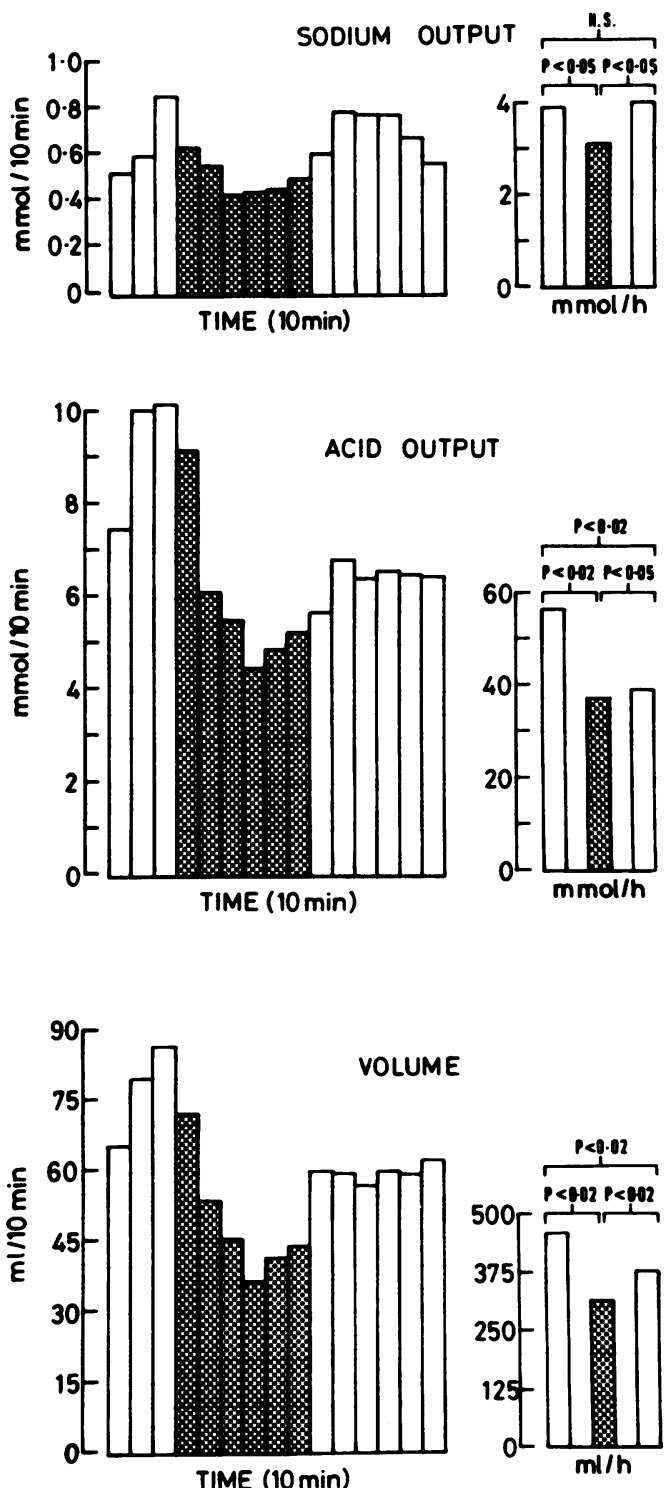

Fig. 2 Sodium, acid output, and observed volume of secretion, before, during, and after sodium taurocholate (NaTC) instillation in six subjects. Medians of the 10 minute and calculated hourly collections during different periods are shown together with statistical analysis. 


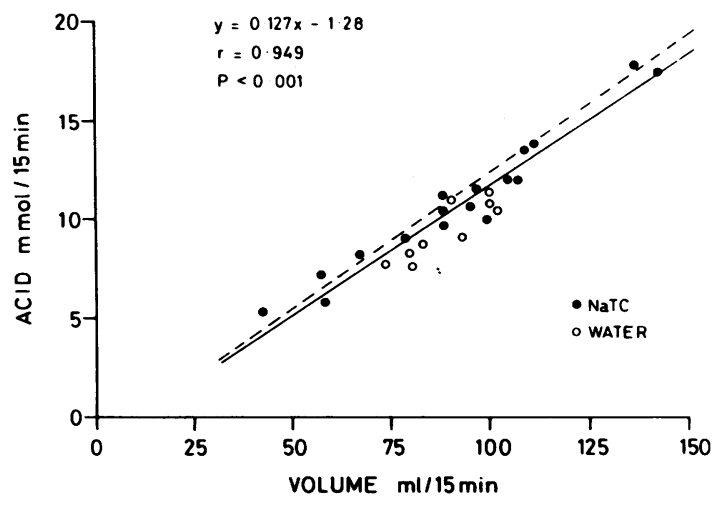

Fig. 3 Relationship between the acid output and volume of secretion in both control and test patients with duodenal ulceration. - - - regression line of Hobsley and Silen, ${ }^{\prime \prime}$ shown for comparison.

$\mathrm{p}<0.001)$ and the regression line was similar to that found by Hobsley and Silen. ${ }^{11}$

\section{Discussion}

The control studies showed that the observed volumes of secretion and the acid output during the different periods of the experiment remained constant. This suggests that the rates of secretion as measured and expressed in this study were accurate, as a plateau of stimulated secretion was achieved and maintained during pentagastrin infusion. Although water has been claimed to be a gastric stimulant, ${ }^{12}$ it did not alter the secretion rates in these studies. It is probable that its stimulatory effect has been masked by the maximal stimulation achieved by pentagastrin.

The reduction in the output of acid and the volume of secretion during sodium taurocholate instillation confirms Davenport's findings. ${ }^{3}$ Davenport attributed the reduction in acid output to mucosal injury caused by bile salts resulting in hydrogen ion loss into the mucosa with sodium moving from the mucosa into the gastric lumen. The acid hyposecretion associated with gastric ulceration is thus generally believed to be due to such a mechanism induced by bile salts. ${ }^{34}$ In the present study, however, during NaTC instillation when the acid output decreased the sodium output also decreased. This is contrary to the requirements of the back-diffusion theory, which would entail an increased output of sodium.

Our results show during NaTC instillation, a concomitant reduction in both hydrogen ion output and volume that is consistent with the two component hypothesis of gastric secretion as modified by Makhlouf $e t a^{13}$ and Hobsley and Silen. ${ }^{11}$ This is shown in Fig. 3 where our results, plotted against the regression line of Hobsley and Silen, ${ }^{11}$ clearly show that the pattern of the electrolytes in gastric secretion in our subjects is similar to theirs. The reduction in sodium output when the volume of secretion was depressed is consistent with Hobsley's ${ }^{10}$ contention that the acid component contains some sodium in contrast with the views of Makhlouf and co-workers ${ }^{13}$ that it contains none. The slopes of the two regression lines depend on the hydrogen ion concentrations of the acid component and are obviously similar in both studies. The intercepts which depend on the volume and concentration of the alkali in the apparent alkaline component are clearly identical. As the apparent alkaline component is the sum of the true alkaline component secreted by the stomach, swallowed saliva, and reflux from the duodenum, this finding of no change in the apparent alkaline component suggested that reflux remained the same in all subjects. This fact was illustrated mathematically by the calculations from the reflux formula which appears to be fairly accurate and applicable even when solutions are instilled into the stomach - a factor which has not been considered before. To summarise, the low sodium output when NaTC was instilled into the stomach is explicable in terms of a lower output of sodium-containing acid component in combination with an unchanged alkaline component.

The findings in an experimental in vivo model using bile salts ${ }^{6}$ failed to provide evidence for the back-diffusion theory, though aspirin in the same model gave results consistent with back-diffusion. ${ }^{14}$ In the present study, when sodium taurocholate instillation was stopped the volume of secretion and the acid output increased but failed to reach the preinhibition levels, this probably being due to the stomach retaining some of the instilled bile salts, although this was not measured. If gastric aspirates had been collected for a further period of time it is likely that complete recovery would have been achieved.

The recovery that was observed suggests that sodium taurocholate caused functional inhibition of the parietal cells rather than the structural disruption of the gastric mucosa. It would appear that, although irritants such as aspirin disrupt the gastric mucosal barrier, bile salts may directly inhibit the parietal cells.

\section{References}

1 Smith GM. An experimental study of the relation of 
bile to ulceration of the mucous membrane of the stomach. J Med Res 1914; 30: 147-51.

$2 \mathrm{Du}$ Plessis DJ. Pathogenesis of gastric ulceration. Lancet 1965; 1 : 974-8.

3 Davenport HW. Is the apparent hyposecretion of acid by patients with gastric ulcer a consequence of a broken barrier to diffusion of hydrogen ions into the gastric mucosa. Gut 1965; 6: 513.

4 Richie WP Jr. Bile acids, the 'barrier' and refluxrelated clinical disorders of the gastric mucosa. Surgery 1977; 82: 192-200.

5 Davenport HW, Warner HA, Code CF. Functional significance of gastric mucosal barrier to sodium. Gastroenterology 1964; 47: 142-52.

$6 \mathrm{El}$ Masri SH, Lewin MR, Clark CG. In vivo effects of bile salts on acid secretion by the rat stomach. Gut 1977; 18: 405-6.

7 Thomson JPS, Russell RGG, Hobsley M. Doublelumen tube for gastric secretion studies. Br Med J 1973; 3: 175.

8 Hassan MA, Hobsley M. Positioning of subject and of nasogastric tube during a gastric secretion study. $\mathrm{Br}$
Med J 1970; 1: 458-60.

9 Hoare AM, Keighley MRB, Starkey B, AlexanderWilliams J. Measurement of bile acids in fasting gastric aspirates: an objective test for bile reflux after gastric surgery. Gut 1978; 19: 166-9.

10 Hobsley $M$. Pyloric reflux: a modification of the two-component hypothesis of gastric secretion. Clin Sci Mol Med 1974; 47: 131-41.

11 Hobsley M, Silen W. The relation between the rate of production of gastric juice and its electrolyte concentration. Clin Sci 1970; 39: 61-75.

12 Bergein O, Rehfuss ME, Hawk P. Gastrointestinal studies III. (Studies in water drinking XXI.) Direct demonstration of the stimulatory power of water on the human stomach. J Biol Chem 1914; 19: 345-71.

13 Makhlouf GM, McManus JPA, Card WI. A quantitative statement of the two-component hypothesis of gastric secretion. Gastroenterology 1966; 51: $149-71$.

14 Galal S, Lewin MR, Clark CG. Effects of aspirin on gastric secretion in the rat. Eur Surg Res 1980; 12: 326-32. 